"These amount to user fees, and the fees are not returned to people who don't use the services," says Mehra. "Physicians are prohibited from extra billing, and this is just a loophole for them to pay for their overhead without proper tracking of usage. Patients are afraid not to pay because they think it will mean less access to their doctors."

Other health care experts believe it's important to distinguish between fees for medically unnecessary services, such as the renewal of a prescription by telephone, and fees for services that may be uninsured but are nonetheless vital to the provision of medically necessary procedures.

Marie-Claude Prémont, an expert in health care law and a teacher at École Nationale d'Administration Publique in Montréal, Quebec, refers to the latter type as accessory fees. Some doctors, for example, require that patients pay to see a dietician before having a colonoscopy or charge a fee for cleaning colonoscopes.

These fees are the true barriers to accessible health care, says Ms. Prémont, not the ones for services that patients want but don't absolutely need. "There is no reason why the public should pay for your cosmetic surgery or if you need a check-up so you can go hiking in Tibet."

Patients may be facing more fees in general because a shift from hospitalto community-based health care has occurred without a corresponding shift in how services are funded. Many medical procedures, such as knee and hip replacements, were once offered only in hospitals, where accessory services are covered by global budgets. Now they are increasingly being offered in clinics that only receive funding for insured services.

"We can't say to a physician that it's wrong to charge for an uninsured service," says Martin, a family physician. "But we can't forget what the spirit of the public system is supposed to be about, which is when you show up in need of health care, you don't get asked to open your wallet. These things are nibbling away at the edges of that." Roger Collier, CMAJ

DOI:10.1503/cmaj.081539

\title{
Health infrastructure a casualty of war on terror within Pakistan
}

A rguing that the health infrastructure in the Federally Administered Tribal Area of Pakistan has been one of the biggest casualties of the "war on terror," the nation's medical association is asking the international medical community to join them in decrying the targetting of health facilities by the United States and Pakistani forces.

"It is an inhuman act on the part of the US and Pakistani forces to target hospitals and deprive the patients of the healthcare facilities. We demand an immediate halt to the dropping of bombs on hospitals," says Dr. Abdul Qadir, president of the Pakistan Doctors' Association.

Since the beginning of the US-led war against terrorism in Pakistan in 2005, there have been attacks on several health facilities in the Federally Administered Tribal Area, which comprises 7 tribal agencies and 6 frontier regions that are collectively bordered on the west by Afghanistan, and on the south and east by Pakistan's Balochistan and NorthWest Frontier provinces, as well as the Indian state of Punjab. The Tribal Area is nominally controlled by the central government of Pakistan and comprised primarily of Pashtun tribes.

In the aftermath of the war in Afghanistan, launched by the US and the United Kingdom with the stated purpose of removing the Taliban regime which had provided safe harbor to Osama bin Laden and al-Qaeda, the remnants of the former Kabul government and its supporters took refuge in the Tribal Area.

In its bid to flush out members of the Taliban, the US has been attacking the Tribal Area, causing unrest among its 3.6 million residents and a lengthy parade of medical casualties.

In September 2006, surgeon Mir Wali Shah and 3 vaccinators were killed by US missile fire over a Tribal Area hospital.

Qadir says many doctors are reluctant to be in the Tribal Area's health facilities and as a consequence, many have taken long leaves of absence or sought transfers to safer facilities.

The Tribal Area, Qadir says, had a

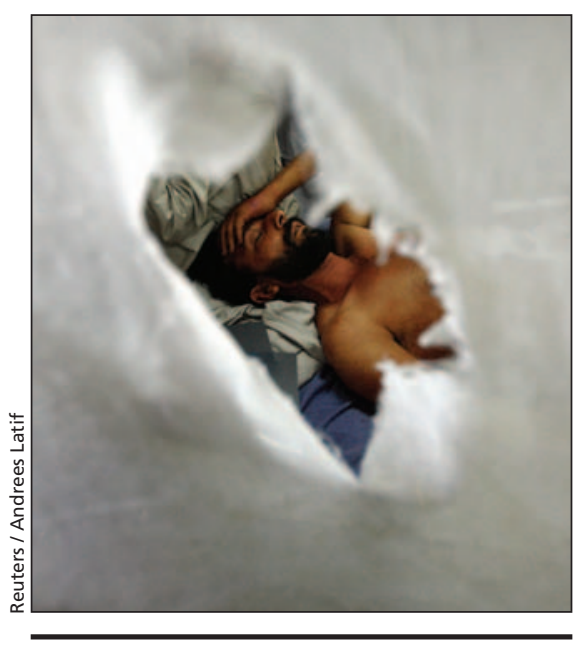

A resident of the North Waziristan town of Bannu, seen through a hole in a sheet at his bedside, is treated for injuries received as a result of rockets fired by militants.

good health-delivery network before 2005 but now is so debilitated that even patients needing minor procedures are brought to Peshawar (the capital of the North-West Frontier Province) for treatment.

Typical is Wajid Khan, who brought his brother Sajid, to the Khyber Teacher Hospital in Peshawar for an appendectomy. "We live very close to the agency headquarters hospital, in Miramshah, North Waziristan Agency, but due to the nonavailability of doctors and staff, we brought our brother here," he says.

Others worry about the strain of added travel.

"We had a full-fledged government hospital in Bajaur Agency. But we transported our mother to Peshawar because of the nonavailability of a specialist there," says Gul Khan, claiming to have paid 1000 rupees (US\$16) for a 3hour taxi ride to transport his mother, who was suffering from hypertension, from the town of Bajaur to Peshawar.

Dr. Zubair Khan, director of Health Services in the Federally Administered Tribal Area, says that since 2002, the number of admissions in hospital and out patient departments has declined dramatically.

Medical Officer Dr. Amjad Ali adds 
that "we saw only 50000 patients in 2006. There were 200000 or more patients before the 'war on terror'." The number of surgeries dropped to 5315 in 2006 from 32000 in 2001.

Physicians, meanwhile, have joined the exodus.

Two years ago, Dr. Bakht Sarwar, 48 , was critically injured when his hospital in Miramshah was hit by a missile. He refused to return to work and is on indefinite leave in Peshawar.

In February 2008, Bajaur Agency surgeon Dr. Abdul Ghani Khan was killed and 3 health department officials were injured in a bomb attack by US forces.

In May, 9 health workers conducting a survey were kidnapped in North Waziristan Agency. They were released after a week.

An acute shortage of medical professionals has now paralyzed the Tribal Area's 26 hospitals, 8 rural health centres and over 400 community health centres.

Where once it had 66 governmentappointed specialists, 435 medical officers, 48 female doctors and 182 nurses apart from nontechnical staff, it is now scrambling for staff.

"Most of them prefer to stay away from their duty places for fear of lack of security there," says one doctor, insisting on anonymity. "Lady health workers, nurses and doctors in North and South Waziristan, Bajaur and Khyber Agencies have been approaching us to get themselves transferred to the NWFP [North West Frontier Province]. Some of them have either taken long leave of absence or were staying home."

Health authorities admit that basic health indicators like infant and maternal mortality rates have worsened and question the Pakistan government's commitment to meet the United Nations Millennium Development Goals by 2015.

For instance, the government was committed to bringing down the infant mortality rate to 44 from the present 116 per 1000 population, and the maternal mortality ratio to 140 from 600 per 100000 live births in the Federally Administered Tribal Area.

But Zubair Khan says that "compared to the rest of the country, the health indicators for FATA are poor." By comparison, the infant mortality rate for all of Pakistan is 103 per 1000 live births and the maternal mortality ratio is 350 per 100000 live births.

Khan, who has appealed to authorities to improve security for health workers, blames the heightened threat of militancy for the poor health services. "Health workers face problems in North and South Waziristan and Khyber Agencies of FATA. They are told not to wear pants and shirts, not to carry cell phones or shave their beards." — Ashfaq Yusufzai, Peshawar, Pakistan

DOI:10.1503/cmaj.081401

\section{Briefly}

Conflicts database: The New York City-based Institute on Medicine as a Profession has launched a publicly accessible database (www.imapny.org /coi_database/) identifying the conflict of interest policies of the United States' 125 academic medical centres in 12 areas, including pharmaceutical industry goodies aimed at influencing medical practice and speaker's bureaus (CMAJ 2008;178[13]:1651-2 and CMAJ 2008; 179[3]:225-6). Organizers say the intent isn't to rank centres but note that among institutions that lack, or have weak, policies are such prestigious centres as Harvard University and the Johns Hopkins School of Medicine.

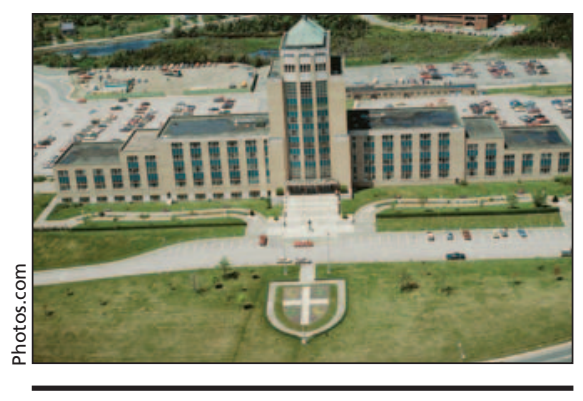

Johns Hopkins University in Baltimore, Maryland.

Code down under: The Australia Medical Council has proposed that the nation's physicians adopt a new draft code of conduct (goodmedicalpractice.org.au/) that requires doctors to disclose whether they've been convicted of a crime or found lacking by another medical licens- ing body. The code obliges Australian physicians to "inform any medical authority with whom you are currently registered without delay if, anywhere in the world: you have been charged with or found guilty of a criminal offence; another professional body has made a finding against you or placed conditions on your medical registration."

Citus, Altius, Fortius: A scant 6 athletes tested positive for performanceenhancing drugs at the 2008 Beijing Summer Games, well under the 27 miscreants who were nabbed at the 2004 Games in Athens, Greece (CMAJ $2008 ; 179[3]: 219-22)$, or the 30-40 that International Olympic Committee president Jacques Rogge had forecast. Skeptics suggested the battery of tests now lags behind athletes' means of disguising drug use but World Anti-Doping Agency Director General David Howman surmised that the drop-off was in part a function of tough pre-Games testing, as over 60 athletes were precluded from even foraying to China because they had tested positive for drugs.

Investigation list: The United States Food and Drug Administration has moved to meet a legislative obligation to post a list of drugs whose safety is under investigation. The list, (www.fda .gov/Cder/aers/potential_signals/potential _signals_2008Q1.htm), culled from the agency's Adverse Event Reporting System, will be updated every 3 months. The FDA said that listing of a drug means only that it has "identified a potential safety issue, but does not mean that FDA has identified a causal relationship between the drug and the listed risk."

Pay hike: The province of Ontario has reached a tentative 4-year agreement (www.oma.org) with its physicians that will see doctors earn a $12.25 \%$ increase in fees, including $3 \%, 2 \%, 3 \%$ and $4.25 \%$ hikes in each of the next 4 fiscal years. By the fourth, the increases will result in Ontario doctors receiving $\$ 9$ billion annually, more than $\$ 1$ billion over the existing fee arrangement. Wayne Kondro, CMAJ

DOI:10.1503/cmaj.081505 